\title{
Ischemic hepatitis with infectious endocarditis: A case report
}

\author{
HIROSHI OKANO ${ }^{1}$, RYO OKADO ${ }^{2}$, HISATO ITO ${ }^{3}$, HIROKI ASAKAWA ${ }^{1}$, KENJI NOSE $^{1}$, SATOMI TSURUGA $^{1}$, \\ TOMOMASA TOCHIO ${ }^{1}$, HIROAKI KUMAZAWA ${ }^{1}$, TAKASHI SAKUNO ${ }^{1}$, YOSHIAKI ISONO ${ }^{1}$, HIROKI TANAKA ${ }^{1}$, \\ SHIMPEI MATSUSAKI ${ }^{1}$, TOMOHIRO SASE ${ }^{1}$, TOMONORI SAITO ${ }^{1}$, KATSUMI MUKAI $^{1}$ and AKIRA NISHIMURA ${ }^{1}$ \\ Departments of ${ }^{1}$ Gastroenterology and ${ }^{2}$ Cardiology, Suzuka General Hospital, Suzuka, Mie 513-8630; \\ ${ }^{3}$ Department of Thoracic and Cardiovascular Surgery, School of Medicine, Mie University, Tsu, Mie 514-8507, Japan
}

Received June 29, 2021; Accepted September 2, 2021

DOI: $10.3892 /$ br.2021.1473

\begin{abstract}
A 58-year-old woman was admitted to Suzuka General Hospital with fever. She was diagnosed with infectious endocarditis based on the presence of anterior mitral leaflet vegetation on the echocardiography analysis and isolation of Pseudomonas guariconensis by blood culture. During treatment, the hepatic enzymes levels, including aspartate aminotransferase (AST), alanine aminotransferase (ALT), lactate dehydrogenase (LDH) and alkaline phosphatase (ALP) were increased without any abdominal symptoms. Prolonged prothrombin time (PT) and prothrombin time international normalized ratio were observed, and acute hepatic failure was diagnosed. However, the hepatic injury resolved spontaneously with restoration of the PT value after the hepatic enzymes (AST, ALT, LDH and ALP) peaked. Diffusion-weighted imaging of hepatic magnetic resonance imaging showed diffuse high intensity of the entire liver except for part of the left lobe. The hepatic injury was diagnosed as ischemic hepatitis caused by embolization from the vegetation associated with infectious endocarditis. The recovery from hepatic ischemia was thought to be due to hepatic blood supply from extrahepatic collateral blood. After antibiotic treatment, the patient underwent resection of the vegetation on the anterior mitral valve leaflet. Hepatic artery occlusion is rare, but it may cause severe hepatic complications. During follow-up of infectious endocarditis, clinicians should be aware of the potential for whole organ ischemic damage caused by vessel occlusion, as well as hepatic ischemic damage.
\end{abstract}

\section{Introduction}

Ischemic hepatitis, also known as hypoxic hepatitis or shock liver, is a clinical syndrome frequently encountered in

Correspondence to: Dr Hiroshi Okano, Department of Gastroenterology, Suzuka General Hospital, 1275-53 Yasuduka-cho, Suzuka, Mie 513-8630, Japan

E-mail: oohh1969@yahoo.co.jp

Key words: acute hepatitis, hepatic artery occlusion, complication, hypoperfusion critically ill patients, and represents a complication of underlying cardiac, circulatory or respiratory failure without any other known cause of acute hepatitis $(1,2)$. The most important cause of ischemic hepatitis is hypotension, such as cardiogenic shock. However, a documented hypotensive event is seen in only $50 \%$ of ischemic hepatitis cases (3). These cases of ischemic hepatitis without documented hypotensive events are assumed to include both cases in which transient subclinical hypotension was overlooked and cases with hepatic tissue injury from hepatic hypoperfusion without systemic hypotension (1). The present report describes a rare case of ischemic hepatitis caused by hepatic artery occlusion during the treatment of infectious endocarditis. A case of acute hepatic injury during the follow-up of infectious endocarditis was observed. The acute hepatic injury occurred without any abdominal symptoms and showed severe hepatic failure with $<40 \%$ of prothrombin time (PT), and the hepatic injury recovered spontaneously. Viral hepatitis or autoimmune hepatic diseases were not detected, and the hepatic injury was diagnosed as ischemic hepatitis that had derived from hepatic hypoperfusion via hepatic artery occlusion with infectious endocarditis. The spontaneous restoration of hepatic blood flow was presumed to be supplied from the extrahepatic blood flow, not recanalization of the hepatic artery. After the ischemic hepatitis was cured, the patient did not exhibit any signs of hepatic injuries.

\section{Case report}

A 58-year-old woman was referred to Suzuka General Hospital with a primary complaint of fever. She had been treated for systemic lupus erythematosus (SLE) with tacrolimus $2 \mathrm{mg} / \mathrm{day}$ per os (PO) and prednisolone $5 \mathrm{mg} /$ day PO. She had no rash or arthritis, and her laboratory data on admission showed no SLE activity (Table I). She had right-sided hemiparesis caused by a cerebrovascular event 30 years earlier. On admission, her temperature was $>39^{\circ} \mathrm{C}$, and her laboratory data showed a white blood cell count (WBC) of $15,000 \times 10^{4} / \mu 1$, C-reactive protein (CRP) levels of $10.55 \mathrm{mg} / \mathrm{dl}$ and procalcitonin levels of $60.43 \mathrm{ng} / \mathrm{ml}$ (Table I). Physical examination did not show any progression of paralysis. Her systolic blood pressure was maintained at $>100 \mathrm{mmHg}$, and she did not have chest symptoms, tachypnea or mental status changes. Her pulse rate was 80 beats per minute and regular. Her chest X-ray did not show any abnormal findings. Her electrocardiogram did not show 
atrial fibrillation, ST elevation and/or ST depression. Although she underwent chest, abdominal, and pelvic computed tomography for identification of the focus of the infection, it could not be found. However, she was found to have a 12-mm-diameter vegetation on the anterior mitral valve leaflet on echocardiography, and thus was diagnosed with infectious endocarditis due to isolation of Pseudomonas guariconensis from the blood culture on day 1. Antibiotic therapy for her infectious endocarditis was started (Fig. 1); ceftriaxone sodium hydrate $2 \mathrm{~g} /$ day and daptomycin $175 \mathrm{mg}$ /day were started empirically. On day 2, the antibiotics were changed to meropenem hydrate $1 \mathrm{~g} /$ day because of the detection of Gram-negative rods on Gram staining of the patient's blood.

After starting treatment with antibiotics, the blood cultures on days 9 and 16 were negative. Her high fever $\left(>38^{\circ} \mathrm{C}\right)$ continued for 9 days after starting antibiotics, with a peak temperature of $39.6^{\circ} \mathrm{C}$; however, her temperature decreased to $<38^{\circ} \mathrm{C}$ after day 10 .

On day 1, the laboratory data reflecting liver function showed aspartate aminotransferase (AST) levels of 69 IU/1, alanine aminotransferase (ALT) levels of 26 IU/1, lactate dehydrogenase (LDH) levels of 434 IU/1 and alkaline phosphatase (ALP) levels of 189 IU/1 (Table I), and these values remained stable until day 6 (Fig. 1). However, on day 10, the hepatic enzyme values of AST, ALT and LDH increased to 663, 492 and 708 IU/1, respectively. Hypotension had not been noted until these hepatic enzyme elevations were seen. Anti-hepatitis A virus IgM antibody, hepatitis B virus surface antigen, anti-hepatitis B virus core IgM antibody, HCV RNA, hepatitis E virus IgA antibody, anti-cytomegalovirus IgM antibody and anti-Epstein-Barr Virus IgM antibody were negative.

Initially, it was suggested that the elevation of these hepatic enzyme values was due to drug-induced liver injury, and antibiotic therapy was thus changed to cefozopran hydrochloride $2 \mathrm{~g} /$ day and gentamicin sulfate (GM) $40 \mathrm{mg}$ /day on day 10 (Fig. 1). On day 11, GM was changed to ciprofloxacin $400 \mathrm{mg} /$ day due to concerns regarding renal side effects. However, the levels of hepatic enzymes, including AST, ALT, LDH and ALP, continued to increase to 1,176, 1,150, 1,132 and $727 \mathrm{IU} / 1$ on day 14 , respectively. On the other hand, she had no abdominal symptoms and no mental status changes. On day 15, these values increased to 3,157 IU/1 for AST, 2,945 IU/1 for ALT and 3,093 IU/1 for LDH. With respect to fibrin/fibrinogen degradation products (FDP) and D-dimer, these values decreased (FDP, $12 \mathrm{mg} / \mathrm{ml}$ on day 16; D-dimer, $8.2 \mu \mathrm{g} / \mathrm{ml}$ on day 16$)$.

At the time, it was hypothesized that the hepatic injury was caused by hepatic artery occlusion, as multiple emboli to her brain had been seen on the diffusion-weighted imaging of magnetic resonance imaging (MRI) on day 8 as multiple high-intensity spots (Fig. 2). Abdominal MRI showed a diffuse high-intensity signal of the whole liver, except for the left hepatic lobe on day 15 (Fig. 3A). Simultaneously high-intensity spots were seen in bilateral kidneys (Fig. 3B). The apparent diffusion coefficient (ADC) map showed low signal intensity of the right hepatic lobe (Fig. 3C). Unlike the MRI of the brain and kidney, the hepatic MRI showed no high-intensity spots. Because the bacteremia improved with antibiotic treatment, and WBC and CRP levels decreased at the time of hepatitis onset, hepatic artery embolization caused by destruction of
Table I. Laboratory data on admission.

Factor

Value

Complete blood count

White blood cell count

Segmented cell

Red blood cell count

Hemoglobin

Hematocrit

Value

$15,000 / \mu 1$

$90 \%$

$305 \times 10^{6} / \mu 1$

$9.8 \mathrm{~g} / \mathrm{dl}$

$27.9 \%$

Platelet

$17.2 \times 10^{4} / \mu 1$

Coagulation

Prothrombin time

$57 \%$

Prothrombin time-international

1.38

normalized ratio

Fibrin/fibrinogen degradation products

$27.4 \mathrm{mg} / \mathrm{ml}$

D-dimer

Fibrinogen

$11.4 \mathrm{mg} / \mathrm{ml}$

$468 \mathrm{mg} / \mathrm{dl}$

Immunochemistry

Anti nuclear antibody

40

Anti-DNA Ab

Lupus anti-coagulant

$<2.0 \mathrm{IU} / \mathrm{ml}$

$<0.7$

Anti-cardiolipin $\beta 2$-glycoprotein 1

$4.3 \mathrm{U} / \mathrm{ml}$

Anti-cardiolipin Ab

$8.4 \mathrm{U} / \mathrm{ml}$

Chemistry

Total protein

$5.4 \mathrm{~g} / \mathrm{dl}$

Albumin

Aspartate aminotransferase

$2.8 \mathrm{~g} / \mathrm{dl}$

$69 \mathrm{IU} / 1$

Alanine aminotransferase

$26 \mathrm{IU} / 1$

Lactate dehydrogenase

$434 \mathrm{IU} / 1$

$189 \mathrm{IU} / \mathrm{l}$

$93 \mathrm{IU} / 1$

$\gamma$-glutamyltransferase

$1,271 \mathrm{IU} / 1$

Creatine kinase

$0.8 \mathrm{mg} / \mathrm{dl}$

$0.1 \mathrm{mg} / \mathrm{dl}$

$199 \mathrm{IU} / \mathrm{l}$

Direct bilirubin

$45.2 \mathrm{mg} / \mathrm{dl}$

Blood urea nitrogen

$2.43 \mathrm{mg} / \mathrm{dl}$

Creatinine

$130 \mathrm{mEq} / \mathrm{l}$

$5.0 \mathrm{mEq} / \mathrm{l}$

$98 \mathrm{mEq} / 1$

$80 \mathrm{mg} / \mathrm{dl}$

Blood sugar

C-reactive protein

$10.55 \mathrm{mg} / \mathrm{dl}$

Procalcitonin

$60.43 \mathrm{ng} / \mathrm{ml}$

Serology

IgG

$982 \mathrm{mg} / \mathrm{dl}$

$168 \mathrm{mg} / \mathrm{dl}$

$9 \mathrm{mg} / \mathrm{dl}$

$\mathrm{Ab}$, antibody; Ig, immunoglobulin.

the vegetation on the mitral valve was suspected. Abdominal ultrasonography showed no stenosis, mass, obstruction and/or collapse of the hepatic portal vein (Fig. 4). 

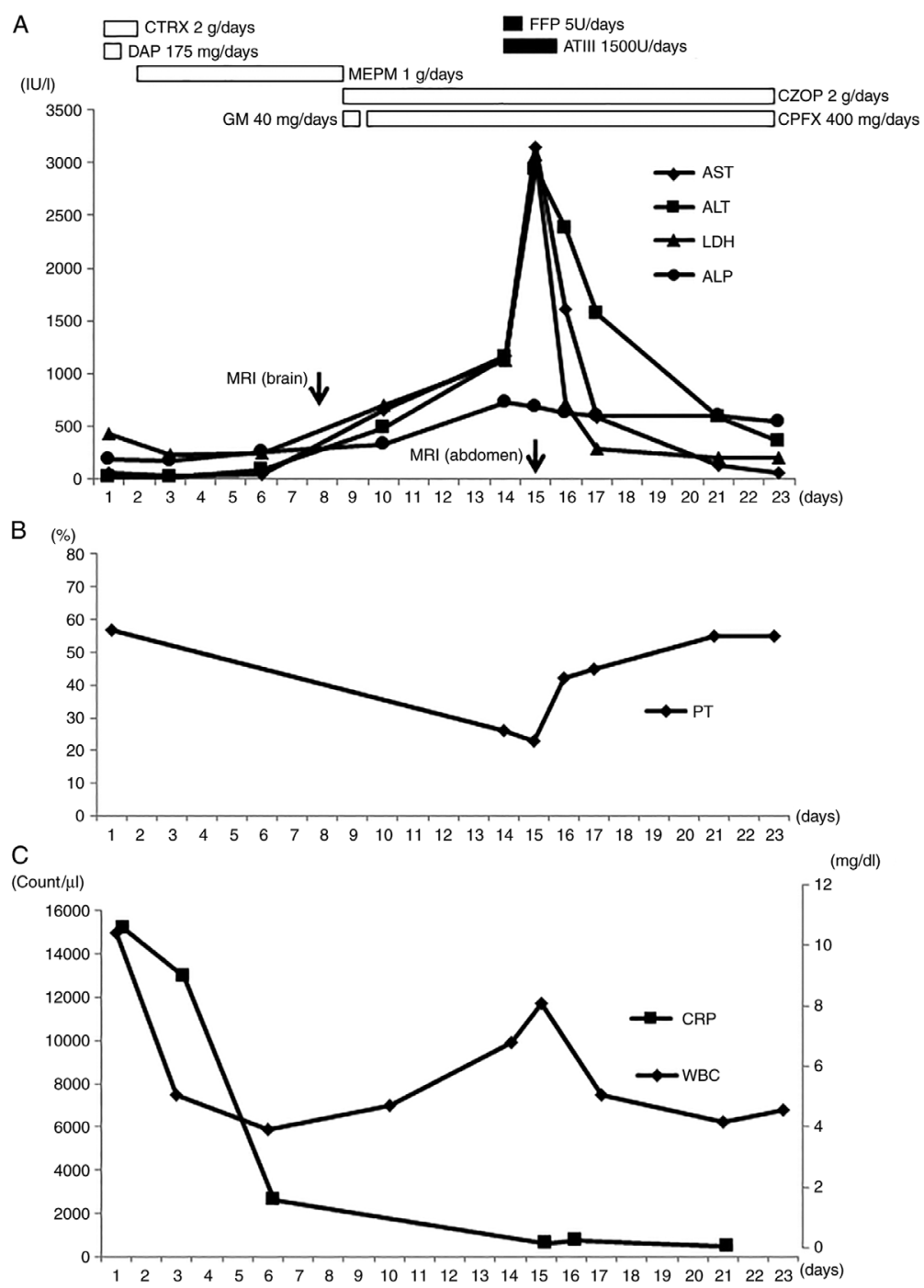

Figure 1. Clinical course of the patient. (A) AST, ALT, LDH and ALP, (B) PT, (C) WBC and CRP levels over the course of observation. AST, aspartate aminotransferase; ALT, alanine aminotransferase; LDH, lactate dehydrogenase; ALP, alkaline phosphatase; PT, prothrombin time; WBC, white blood cell count; CRP, C-reactive protein; CTRX, ceftriaxone sodium hydrate; DAP, daptomycin; MEPM, meropenem hydrate; GM, gentamicin sulfate; CZOP, cefozopran hydrochloride; CPFX, ciprofloxacin; FFP, fresh frozen plasma; ATIII, antithrombin III; MRI, magnetic resonance imaging.

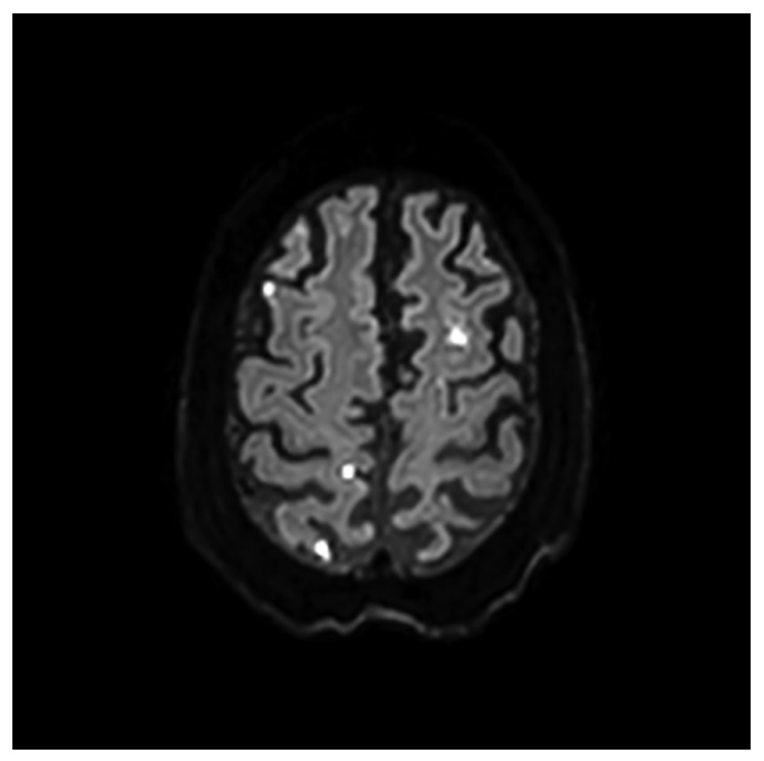

Figure 2. Magnetic resonance imaging axial tomographic image of the brain (diffusion-weighted imaging) on day 8.
In addition, prolonged PT and PT-international normalized ratio were observed (Fig. 1 and Table II). Although the WBC was $>10,000 \times 10^{4} / \mu 1$, CRP was within the normal range. The disseminated intravascular coagulation (DIC) scoring showed that the total score was 1 , and DIC was not diagnosed based on JSTH's provisional draft DIC diagnostic criteria (4).

Ischemic hepatitis due to hepatic artery embolization and acute liver failure were diagnosed. Fulminant hepatitis was not diagnosed due to the lack of hepatic encephalopathy. She was treated with fresh frozen plasma and antithrombin III for the acute liver failure. Steroid pulse treatment was not administered given the infectious disease. On day 16 , the transaminase values decreased to 1,615 IU/l for AST, 2,374 IU/l for ALT, $711 \mathrm{IU} / 1$ for LDH and $626 \mathrm{IU} / 1$ for ALP, and PT was restored. These transaminase values decreased further to $59 \mathrm{IU} / 1$ for AST, $355 \mathrm{IU} / 1$ for ALT, $206 \mathrm{IU} / 1$ for LDH and $550 \mathrm{IU} / 1$ for ALP by day 23 .

On day 23, the patient was transferred to another advanced treatment hospital and underwent resection of the vegetation on the anterior leaflet of the mitral valve. The resected vegetation 


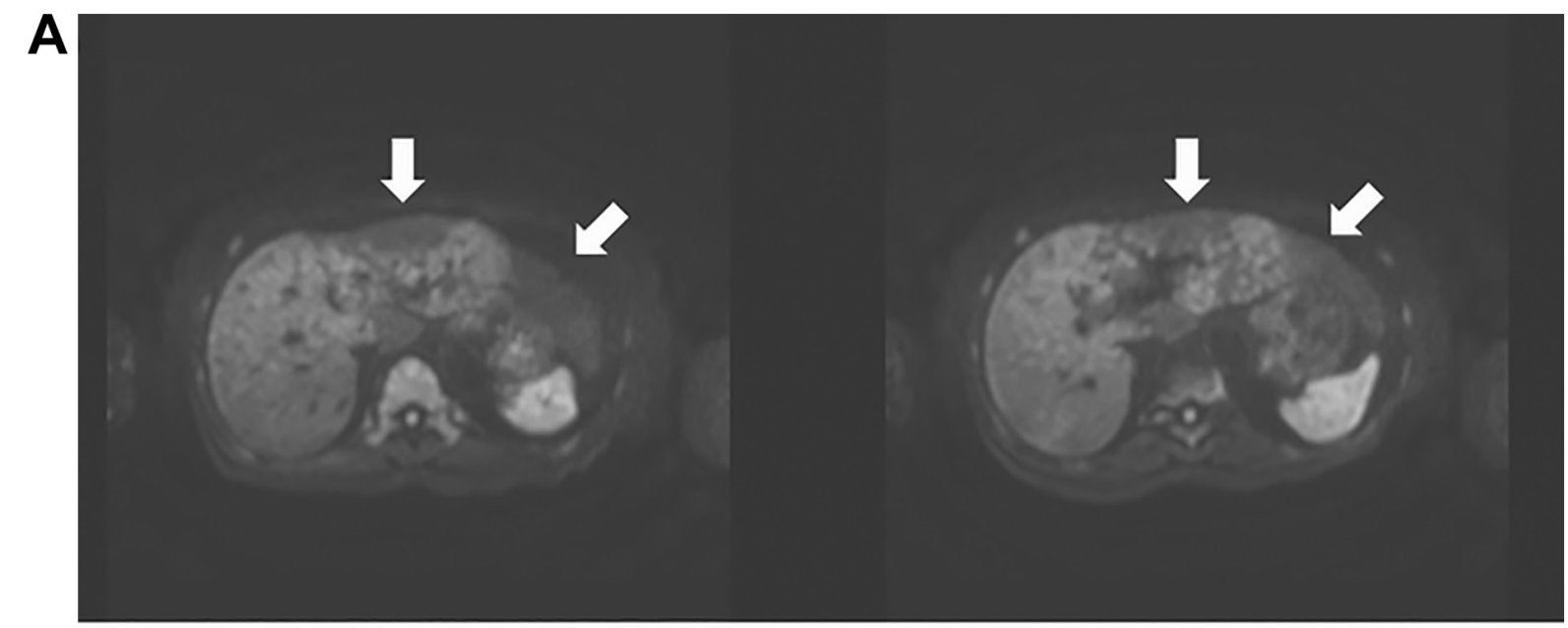

B
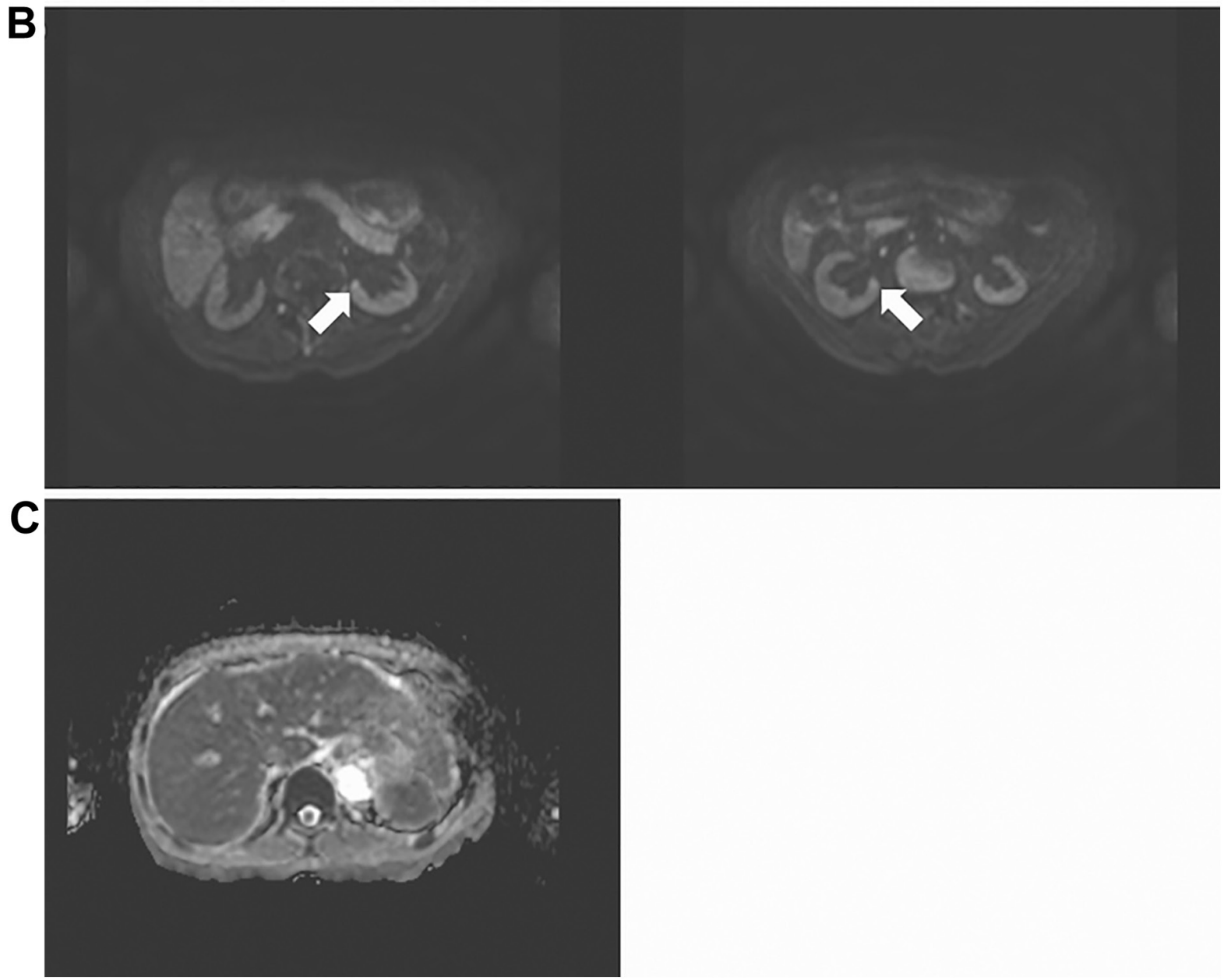

Figure 3. MRI images of the liver and kidney. Magnetic resonance imaging axial tomographic images of the (A) liver and (B) kidneys (diffusion-weighted imaging) on day 15. In (A) the white arrows indicate the areas of low intensity of the liver, whereas in (B) they indicate the high-intensity spots of the kidneys. (C) Apparent diffusion coefficient map of the liver on day 15. MRI, magnetic resonance imaging.

was the size of a rice grain. The pathological analysis was not performed because the specimen of vegetation was inadequate for pathological analysis due to the small size. On day 245 , she was stable with no fever, no symptoms and no hepatic enzyme abnormalities (AST, 18 IU/l; ALT, 12 IU/l; LDH, 233 IU/l; and ALP, 271 IU/l) after treatment.

Oral informed consent, including a statement of agreement to the use of the samples in scientific research, was obtained from the patient in the Outpatient Department of Suzuka
General Hospital. She did not consent to saving of this consent as a document, which was respected and Suzuka General Hospital Ethics Committee agreed to having consent being obtained orally in this case.

\section{Discussion}

Ischemic hepatitis is an hepatic tissue injury that manifests as a result of hypoxia caused by hepatic hypoperfusion. Hepatic 


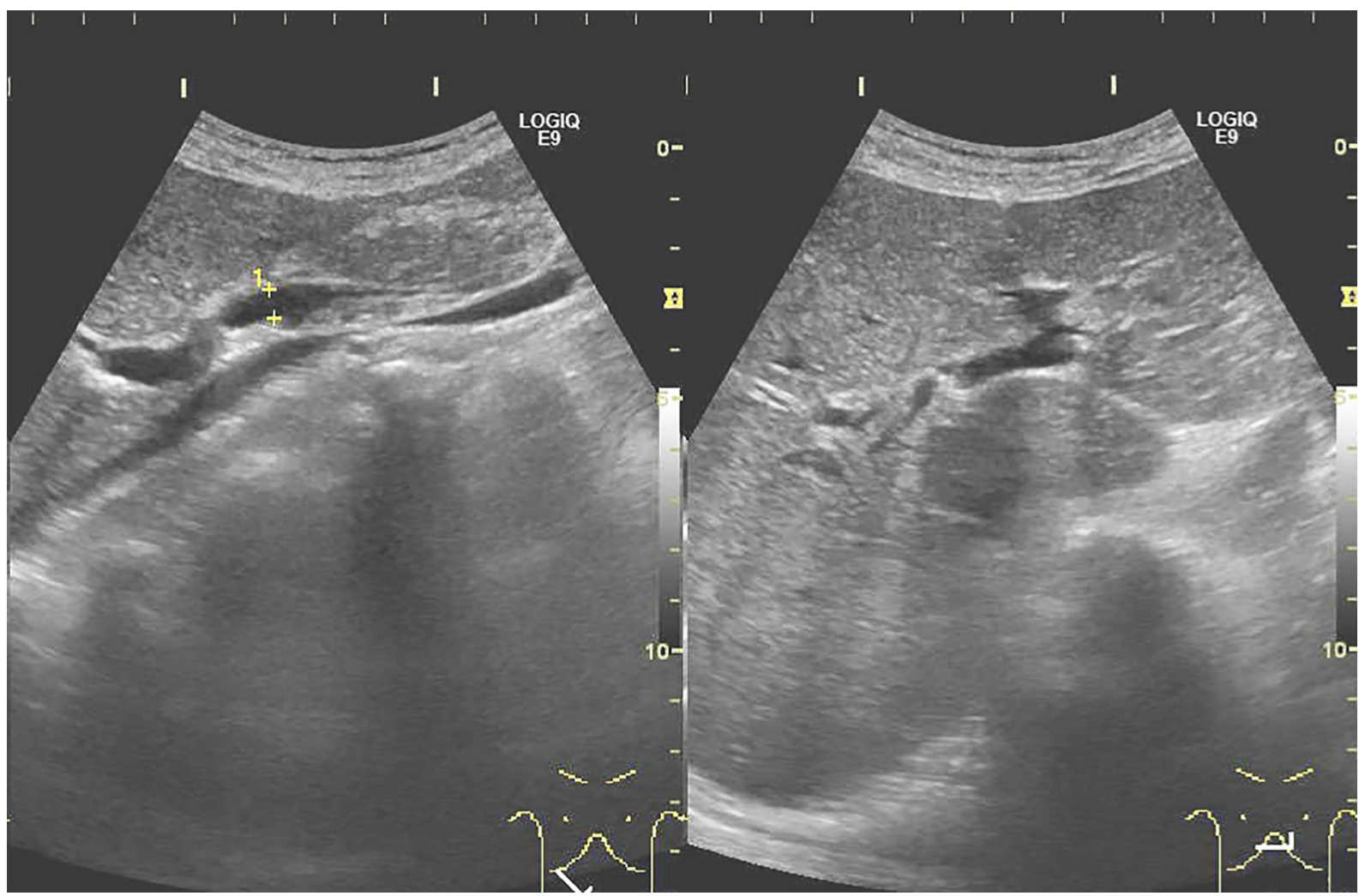

Figure 4. Ultrasonography of the liver on day 15 . There was no mass in the liver, and the portal vein was intact, with no evidence of stenosis, mass, obstruction and/or collapse.

Table II. The laboratory data associated with DIC as well as DIC scoring on day 14.

\begin{tabular}{lcc}
\hline Measurement & Value & $\begin{array}{c}\text { DIC } \\
\text { score }^{\mathrm{a}}\end{array}$ \\
\hline Platelet & $52.2 \times 10^{4} / \mu 1$ & 0 \\
Fibrin/fibrinogen degradation products & $15.3 \mathrm{mg} / \mathrm{ml}$ & 1 \\
Prothrombin time international & 2.29 & 2 \\
normalized ratio & & \\
Antithrombin III & $61 \%$ & 1 \\
Thrombin-antithrombin III complex & $2.6 \mathrm{ng} / \mathrm{ml}$ & 0 \\
Liver failure & $(+)$ & -3 \\
Total DIC score & & 1 \\
\hline
\end{tabular}

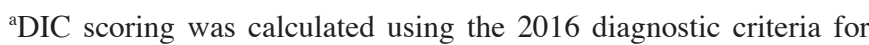
DIC from the Japanese Society on Thrombosis and Hemostasis (4). DIC, disseminated intravascular coagulation.

hypoperfusion is most commonly caused by acute cardiac failure, toxic shock states and respiratory failure (5), but hepatic artery occlusion is a rare cause of significant hepatic ischemia (6). Hepatic artery thrombosis, which can induce hepatic artery occlusion and/or a hepatic artery blood inflow disturbance, is the most common complication following liver transplantation or other surgical procedures (7). However, the current patient had not undergone these operations before onset of the present event.
SLE causes chronic inflammation in multiple organs (8). As SLE is associated with an accelerated atherosclerotic process (8), and patients with SLE show inflammatory involvement of vessels of all sizes (9), SLE may affect hepatic perfusion and induce liver injury due to vasculopathy of hepatic arteries. However, the patient had continued treatment for SLE with prednisolone and tacrolimus during the treatment for the infectious endocarditis, and the elevated hepatic enzyme levels were resolved without increasing the dosage or changing the medication for SLE. Although she had a cerebrovascular event $\sim 30$ years earlier, she did not have any atherosclerotic-associated disease events since then. Thus, SLE may not have been associated with the hepatic injury. Lu et al (10) reported that hepatic arterial aneurysms are associated with SLE; however, the patient was not found to possess any arterial aneurysms involving the hepatic artery.

Although sepsis accounts for $23.4 \%$ of cases of ischemic hepatitis (3), the patient did not develop septic shock during the clinical course, and the infectious endocarditis had been controlled with antibiotic treatment, as shown by the decreasing CRP values and fever. The WBC also decreased until the onset of hepatic injury (Fig. 1). Given the above clinical course, the rebound increase of WBC was assumed to be due to ischemic hepatic tissue injury rather than aggravation of the infectious endocarditis. In this case, multiple cerebral and kidney infarctions developed due to the emboli, which were seen as multiple high-intensity spots on diffusion-weighted imaging of MRI. However, the diffusion-weighted imaging of hepatic MRI did not show multiple high-intensity spots, but a diffuse high intensity for the whole liver except for the 
left hepatic lobe. Angiography of the hepatic artery could not be performed at the time of hepatic injury because of renal dysfunction. As DWI is a widely accepted technique for detecting early ischemic change, especially in neuroradiology (11), it can be assumed that hepatic artery occlusion, probably involving the common hepatic artery, occurred due to embolization, and ischemic hepatitis developed as a result. Based on the theory that restricted or impeded water diffusion is seen in tissues with high cellularity, such as in cytotoxic edema (11), the diffuse high intensity of the whole liver was presumed to reflect the swelling of the hepatic cells by ischemia. An isolated hepatic artery occlusion is usually considered an unlikely cause of significant hepatic ischemia in non-transplant patients and is considered an unlikely cause of significant hepatic ischemia, as there is a dual blood supply to the liver that comes from the portal vein and hepatic artery (7). However, Béland et al (6) reported a case of fulminant hepatitis caused by common hepatic artery occlusion in a patient with a history of atrial fibrillation (6). As the values of FDP and D-dimer decreased after starting treatment, thrombosis was unlikely to have caused ischemic hepatitis in the present case. Von Glinski et al (12) reported a case of ischemic hepatitis that developed secondary to celiac trunk stenosis as a result of cephalad displacement of the celiac trunk and compression of the artery by the diaphragmatic ligament. Zhang et al (13) reported 19 cases of transient liver enzyme elevation alone after complete occlusion of hepatic arterial flow. Thus, the present case was likely ischemic hepatitis caused by hepatic artery occlusion despite a non-portal venous blood flow disturbance. In addition, thrombosis was unlikely to have caused ischemic hepatitis in the present case as the values of FDP and D-dimer decreased after starting treatment.

The incidence of embolic events is high in patients with infective endocarditis (14). Embolic events occur after a median time of 7 days following the start of adequate antibiotic therapy (15), and $65-71.4 \%$ of cases, occur within $\sim 2$ weeks $(15,16)$. Certain organ arterial emboli in infective endocarditis can cause lethal and/or severe outcomes (17-19). In the present case, the hepatic artery embolic event occurred in the second week after starting antibiotic treatment. The antibiotic treatment was effective at the time of hepatitis onset, and thus it can be assumed that the source of embolization was not so much septic emboli, but the destruction of the mitral valve vegetation, as septic emboli were unlikely to occur unless bacteremia persisted. The emboli of the brain and kidney may have been caused by septic emboli that occurred before antibiotic treatment, and thus the MRI of the liver may have been different from that of the brain and kidneys.

In the present case, the patient also had severe hepatic dysfunction with PT $<40 \%$, but fulminant hepatitis did not develop. The case of Béland et al (6) showed severe hepatic enzyme elevations due to hepatic artery occlusion, with AST $>15,000 \mathrm{IU} / 1$ and ALT >6,000 IU/1. On the other hand, the peak AST and ALT values were only 3,157 and 2,945 IU/1 in the present case, respectively. The difference in hepatitis severity between the present case and that of Béland et al (6) may be due to the difference in the cause of arterial occlusion (embolization derived from destruction of vegetation and thrombosis). Furthermore, the diffusion-weighted imaging of hepatic MRI showed a low-intensity area in part of the liver in the present case. These low-intensity areas were assumed to reflect the area that had not been affected by hepatic hypoperfusion. These areas were in the left lobe of the liver, and blood perfusion via extrahepatic collateral arteries including the left inferior phrenic artery or the left gastric artery $(20,21)$ might have resulted in rescue of hepatic tissue from the hypoperfusion damage caused by the hepatic artery occlusion. Cho et al (22) reported that no ischemic liver injuries developed after hepatic artery embolization with no portal vein stenosis and bilobar hepatic arterial flow via the left hepatic artery aberrantly arising from the left gastric artery or from the common hepatic artery. In addition, Sato et al (23) suggested an association with hepatic failure related to hepatic arterial embolization for hemostasis and the absence of hepatic collaterals. The ischemic hepatitis resolved without any treatment for hepatic occlusion, and the reason for the spontaneous resolution of the hepatic hypoperfusion is unknown; however, the spontaneous recovery of hepatitis in the present case may have reflected hepatic perfusion recovery via extrahepatic collateral blood inflow rather than recanalization of the hepatic artery. No hepatic injury may occur under intact portal venous blood flow and efficient collateral extrahepatic arterial blood flow at the time of hepatic arterial occlusion. Although an attempt was made to visualize the blood supply from extrahepatic collaterals after recovery, it was impossible to detect the collateral vessels by magnetic resonance angiography due to limitations of its resolving power.

In conclusion, a case of ischemic hepatitis that developed as a complication of infectious endocarditis is reported on. Although the patient developed acute liver failure, the hepatitis did not progress to fulminant hepatitis, and instead resolved spontaneously. The possibility of ischemic hepatitis due to hepatic artery hypoperfusion caused by embolization when hepatitis occurs during the follow-up of patients with infectious endocarditis should thus be considered. Additionally, the potential for whole-organ ischemic damage caused by vessel occlusion when treating a case of infectious endocarditis should also be taken into consideration.

\section{Acknowledgements}

Not applicable.

\section{Funding}

No funding was received.

\section{Availability of data and materials}

The datasets used and/or analyzed during the current study are available from the corresponding author on reasonable request.

\section{Authors' contributions}

HO was involved in the conception and design of the study, writing the manuscript and preparing the tables. RO, HA, KN, ST, TT, HK, TSakuno, YI, HT, SM, TSase, TSaito, KM and AN collected the data. HI operated on the patient and collected the data. All authors revised the manuscript. All authors have 
read and approved the final manuscript. HO and AN confirm the authenticity of all of the raw data.

\section{Ethics approval and consent to participate}

Oral informed consent, including a statement of agreement to the use of the samples in scientific research, was obtained from the patient in the Outpatient Department of Suzuka General Hospital. She did not consent to saving of this consent as a document, which was respected and Suzuka General Hospital Ethics Committee agreed to having consent being obtained orally in this case.

\section{Patient consent for publication}

The patient gave consent for the publication of this study.

\section{Competing interests}

The authors declare that they have no competing interests.

\section{References}

1. Lightsey JM and Rockey DC: Current concepts in ischemic hepatitis. Curr Opin Gastroenterol 33: 158-163, 2017.

2. Shen BQ, Dong LQ and Ma Y: Research progress of ischemic hepatitis. Zhonghua Gan Zang Bing Za Zhi 26: 707-709, 2018 (In Chinese).

3. Tapper EB, Sengupta N and Bonder A: The incidence and outcomes of ischemic hepatitis: A systematic review with meta-analysis. Am J Med 128: 1314-1321, 2015.

4. Asakura H, Takahashi H, Uchiyama T, Eguchi Y, Okamoto K, Kawasugi K, Madoiwa S and Wada H; DIC subcommittee of the Japanese society on thrombosis and hemostasis: Proposal for new diagnostic criteria for DIC from the Japanese Society on thrombosis and hemostasis. Thromb J 14: 42, 2016.

5. Waseem $\mathrm{N}$ and Chen PH: Hypoxic hepatitis: A review and clinical update. J Clin Transl Hepatol 4: 263-268, 2016.

6. Béland M, Despatis MA and Gahide G: Hepatic artery emboli causing fulminant hepatitis. J Vasc Interv Radiol 30: 1613, 2019.

7. Elsayes KM, Shaaban AM, Rothan SM, Javadi S, Madrazo BL, Castillo RP, Casillas VJ and Menias CO: A comprehensive approach to hepatic vascular disease. Radiographics 37: 813-836, 2017.

8. Zanatta E, Colombo C, D'Amico G, d'Humières T, Dal Lin C and Tona F: Inflammation and coronary microvascular dysfunction in autoimmune rheumatic diseases. Int J Mol Sci 20: E5563, 2019.

9. Barile-Fabris L,Hernández-Cabrera MF and Barragan-Garfias JA: Vasculitis in systemic lupus erythematosus. Curr Rheumatol Rep 16: 440, 2014
10. Lu M, Weiss C, Fishman EK, Johnson PT and Verde F: Review of visceral aneurysms and pseudoaneurysms. J Comput Assist Tomogr 39: 1-6, 2015.

11. Kele PG and van der Jagt EJ: Diffusion weighted imaging in the liver. World J Gastroenterol 16: 1567-1576, 2010.

12. Von Glinski KS, Krettek C, Blauth M and Oldhafer KJ: Hepatic ischemia as a complication after correction of post-traumatic gibbus at the thoracolumbar junction. Spine (Phila Pa 1976) 25: 1040-1044, 2000.

13. Zhang J, Qian HG, Leng JH, Qiu H, Wu JH, Liu BN, Li CP, Wei M, Liu Q, Lv A and Hao CY: Ischemic liver injury after complete occlusion of hepatic artery in the treatment of delayed postoperative arterial bleeding. J Gastrointest Surg 19: 2235-2242, 2015.

14. Fabri J Jr, Issa VS, Pomerantzeff PM, Grinberg M, Barretto AC and Mansur AJ: Time-related distribution, risk factors and prognostic influence of embolism in patients with left-sided infective endocarditis. Int J Cardiol 110: 334-339, 2006.

15. Thuny F, Di Salvo G, Belliard O, Avierinos JF, Pergola V, Rosenberg V, Casalta JP, Gouvernet J, Derumeaux G, Iarussi D, et al: Risk of embolism and death in infective endocarditis: Prognostic value of echocardiography: A prospective multicenter study. Circulation 112: 69-75, 2005.

16. Vilacosta I, Graupner C, San Román JA, Sarriá C, Ronderos R, Fernández C, Mancini L, Sanz O, Sanmartín JV and Stoermann W: Risk of embolization after institution of antibiotic therapy for infective endocarditis. J Am Coll Cardiol 39: 1489-1495, 2002.

17. Castelli JB, Almeida G and Siciliano RF: Sudden death in infective endocarditis. Autops Case Rep 6: 17-22, 2016.

18. Oestreich BA, Sommer P and Armstrong EJ: Coronary artery embolism from infectious endocarditis treated with catheter thrombectomy using a GuideLiner catheter. Catheter Cardiovasc Interv 87: E197-E201, 2016.

19. Schmidt D and Zehender M: Arterial occlusion of the eye in infectious endocarditis. Ophthalmologe 96: 264-266, 1999 (In German).

20. Gwon DI, Ko GY, Yoon HK, Sung KB, Lee JM, Ryu SJ, Seo MH, Shim JC, Lee GJ and Kim HK: Inferior phrenic artery: Anatomy, variations, pathologic conditions, and interventional management. Radiographics 27: 687-705, 2007.

21. Miyayama S, Yamashiro M, Okuda M, Aburano H, Shigenari N, Morinaga $\mathrm{K}$ and Matsui $\mathrm{O}$ : Anastomosis between the hepatic artery and the extrahepatic collateral or between extrahepatic collaterals: Observation on angiography. J Med Imaging Radiat Oncol 53: 271-282, 2009.

22. Cho SK, Kim SS, Do YS, Park KB, Shin SW, Park HS, Choo SW and Choo IW: Ischemic liver injuries after hepatic artery embolization in patients with delayed postoperative hemorrhage following hepatobiliary pancreatic surgery. Acta Radiol 52: 393-400, 2011

23. Sato A, Yamada T, Takase K, Matsuhashi T, Higano S, Kaneda T, Egawa S, Takeda K, Ishibashi T and Takahashi S: The fatal risk in hepatic artery embolization for hemostasis after pancreatic and hepatic surgery: Importance of collateral arterial pathways. J Vasc Interv Radiol 22: 287-293, 2011.

(i) () () This work is licensed under a Creative Commons cc) $\mathrm{EY}$ No ND Attribution-NonCommercial-NoDerivatives 4.0 International (CC BY-NC-ND 4.0) License. 